\title{
O SISTEMA DE OBJECTIVOS FINANCEIROS COMO METODOLOGIA E INSTRUMENTO DE MUDANÇA ORGANIZACIONAL NA GESTÃO DA PME
}

\author{
José Filipe Medeiros de Lucena" \\ Jose.Lucena@esgs.pt
}

\section{RESUMO}

Numa cconomia global, em que é patente a importância das PMEs, como motor da actividade económica constituída por uma realidade diversa, justifica-se o enquadrar da Teoria Financeira no contexto das PMEs, no ambito da problemática do Sistema de Objectivos Financeiros.

Com o teor desta investigação, pretendemos não só sistematizar e desenvolver um corpo térico relativo à problemática do sistema de objectivos financeiros, mas também analisar dentro do contexto das PME's, os principais atributos explicativos dos respectivos modelos.

Utilizando como técnica o modelo de Curchill e Mullins, mostramos como o crescimento sustentado pode ser visto de uma forma dinâmica, destacando as suas potencialidades através da manipulaçäo dos instrumentos de crescimento, e compreendemos' a natureza e análise operacional dos objectivos financeiros e das suas consequências estratégicas, com o modelo de Donaldson.

O texto que hora se publica é um artigo apresentado nas XIV Jornadas L uso Espanholas de Gestão Cientifica, na Universidade dos Açores, em Fevereiro de 2004 e traduz uma súmula de trabalho de Dissertação de Mestrado em Gestão de Empresas.

O autor é docente na Escola Superior de Gestão de Santarém, na Área de Administração Empresarial e Pública, Complexo Andaluz, Apartado 295. 2001 - 904 Santarém (http:// wwwesgs.pt. Email: correio(a)esgs.pt). 


\section{ABSTRACT}

In a global economy, where the importance of the PMEs is clear, as motor of the economic activity consisting by a diverse reality, fitting of the Financial Theory in the context of the PMEs is justified, in the scope of the problematic one of the financial goals system.

With the text of this research, we not only intend systemize and to develop relative a theoretical body to the problematic one of the financial goals system, but also to analyser inside of the context of the industry of Tanneries, the main clarifying attributes of the respective models.

Using as technique the model of Curchill and Mullins, we show as the sustainable growth can be seen of a dynamic form, detaching its potentialities through the manipulation of the growth instruments, and understands the nature and operational analysis of the financial goals and strategic consequences, with the model of Donaldson.

PALAVRAS-CHAVE: Sistema de Objectivos Financeiros; Taxa de Crescimento Sustentável; RONA; Círculo Estratégico; Tesouraria e o Índice Z.

\section{SUMÁRIO}

I-Encuadramento Téórico

I.I - Estrutura Teórica do Crescimento Empresarial

1.2 - Estratégias de crescimento sistemático

I.2.I - Crescimento por "Scaling"

1.2.2 - Crescimento por "Duplication"

I.2.3 - Crescimento por "Granulation"

2 - A Estrutura do Ciclo de Vida Financeiro

2.I - O Crescimento Sustentável

2.1.1 -.. A Taxa de Crescimento Sustentável

2.1.2 - Crescimento real Vs Crescimento sustentável

2.2. - O ciclo operacional de "Cash"

2.3. - O Modelo financeiro de Donaldson

2.3.I - O modelo auto sustentado

2.3.2 - O Ciclo estratégico

3 - Metodologia e Instrumentos de Mudança

3.I-As variáveis 
3.1.1-O Crescimento sustentável

3.1.2-A Rendibilidade

$3.1 .3-$ A Tesouraria

3.1.4-O Indice Z

3.2 - Os Resultados

3.2.1-Considerações prévias

3.2.2 - Análise e reflexão do $S O F$ / empresa

3.2.2.1 - Estrutura Financeira 100

4-Conclusões Gerais e Perspectivas Futuras

Bibliografia

Anexo

Indice de Figuras:

Figura I-Matriz de Produtos e Mercados

Figura 2 - Objectivos Económicos

Figura 3 - O ciclo de vida financeiro

Figura 4-Componentes de um ciclo operacional de Cash

Figura 5-Ciclo de vida das prioridades financeiras da empresa

\section{1 - ENQUADRAMENTO TEÓRICO}

A Teoria Neoclássica, dominou a economia teórica até o último quarto deste último século, e continua ainda a ter um elevado prestígio nos nossos dias. Mas ao longo deste último quarto de século, surgiu uma explosão de nova literatura sobre o comportamento, a gestão, as teorias, as políticas e os negócios das empresas e das organizações.

Para Edith Penrose (1995), existem diversas razões que contribuíram para csta situação: A ascensão ou aparecimento da escola de negócios, o rápido aumento de $\mathrm{PhDs}$ relacionados com a gestão e o negócio nas universidades e o consequente aumento de estudos aplicados de economia a casos de empresas, desobstruindo o caminho para novas maneiras de pensar sobre o emergir natural de um diferente tipo de sociedade industrial, incluindo o desenvolvimento de novas fórmulas de organização empresarial, que são frequentemente estimuladas pela explosão do interesse nas empresas japonesas e no seu sucesso, e mais recentemente pelo crescimento evolutivo do pensamento da economia em geral, cada vez mais entendido pelas limitações explicativas da eficácia "estática" da economia neoclássica no mundo modemo. 
De acordo com Mark Casson (1982), a empresal deve ser vista como um instrumento de exploração de oportunidades do lucro. Assim, os limites ao crescimento da empresa são ajustados pela visão empresarial da equipa de gestão. As oportunidades de lucro existem porque a economia não ajusta instantaneamente e automaticamente a respectiva mudança ao meio ambiente. Assim tão distante desta resposta automática, certamente, existem nela os sinais fornecidos para as oportunidades do lucro. O tipo de oportunidades que gera uma empresa é a oportunidade de corrigir o que seria de outra maneira uma atribuição persistente de recursos numa área particular. Tipicamente a exploração de tal oportunidade requer a criação de um novo mercado, ou ao menos, a extensăo de um já existente.

\section{1 - Estrutura Teórica do Crescimento Empresarial}

Em economia, a palavra "crescimento" pretende expressar apenas o processo de incremento da produção ao longo de um determinado período de tempo. Claro que este conceito tem que ser preciso, para que tenha um significado claro e concreto. Esta precisão provem, umas vezes da forma de medição e, outras, da intenção de distinguir entre os termos económicos, o crescimento do desenvolvimento. O primeiro, relaciona-se com alteraçốes quantitativas do sujeito económico e o segundo com variações qualitativas que podem incluir ou não as primeiras.

De acordo com Penrose (1995), não faz sentido falar de crescimento da empresa no sentido tradicionalmente do termo, como um mero ajuste ou aplicação do tamanho mais conveniente para a mesma, mas sim na existência de um processo interno de desenvolvimento, para a qual a dimensão é apenas uma consequência deste processo.

A justificação deste enfoque, apoia-se fundamentalmente em se considerar a empresa como uma organização, e como tal, o conccito de crescimento tem que se relacionar tanto com os aspectos estruturais ' como com os aspectos comportamentais ${ }^{2}$, atendendo aos diferentes

'Considere-se a dimensão, o número de componentes estruturais ou funcionais, o sistema técnico, a configuração da rede de fluxos reais e dos fluxos de trabalho e o campo de actividade (produtos e mercados).

'Considere-se o sistema de objectivos, o processo de decisão e o poder. 
subsistemas (técnico, humano, de direcção, cultural e de poder) que integram o conceito de empresa complexa e moderna, segundo Bueno Campos (1993), razões para a qual se apresenta válida as seguintes premissas:

a) as características da empresa actual, definidoras de uma complexidade estrutural e de comportamento, dados os factores funcionais e objectivos da mesma, o que permite defini-la como um "conjunto de recursos e capacidades";

b) a dimensão jurídica da empresa desde o carácter unipessoal até ao grupo de sociedades;

c) a capacidade do sistema de gestão e as capacidades dos gestores como impulsionadores do crescimento empresarial;

d) as modalidades de crescimento, cumulativamente diferentes, baseadas em opções de cxpansão e de diversificação;

e) os efeitos promovidos pelas mudanças do meio ambiente e das actividades da empresa;

f) a consideração do crescimento da empresa como uma medida de natureza relativa, mais do que de carácter absoluto.

Na moderna concepção de empresa dos nossos dias, para além do conceito de complexidade, de estrutura jurídica, do incremento dos conhecimentos tecnológicos, da experiência e dos planos de formação, existe um acordo generalizado entre todos os especialistas e teóricos sobre as formas do processo de crescimento empresarial, conhecidas por crescimento interno e crescimento externo. Para além deste acordo doutrinal sobre as formas do processo de crescimento, podemos afirmar que existe também uma aceitação generalizada a

Figura 1 - Matriz de Produtos e Mercados

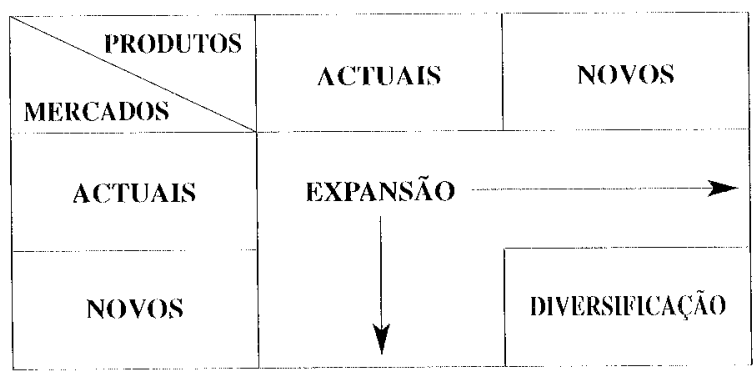

Fonte: H. I. Ansofl 
nível das modalidades genéricas de crescimento, com diferenças importantes entre si, tanto na sua forma como no seu desenvolvimento e gestão, conhecidas pelos termos de "Expansão e Diversificação".

Considerado como uma das principais razões que levaram ao abandono do conceito tradicional do crescimento, como sendo um mero incremento de uma ou mais grandezas económicas da empresa, foi dos efeitos que sobre o processo produzem porventura as alterações no meio envolvente competitivo e na quota de mercado da unidade económica.

Em face das razöes apresentadas, podemos apresentar o conceito de crescimento empresarial, com um carácter dinâmico exposto pela comissão de estudos da AECA ${ }^{3}$ :

"O crescimento da empresa representa o desenvolvimento que a mesma está a alcançar, manifestado tanto pelo incremento das grandezas económicas que explicam a sua actividade como pelas mudanças observadas na sua estrutura económica e organizativa”.

Os objectivos cconómicos ou genéricos, próprios do sistema de uma organização apresentam a característica de estarem plenamente interrelacionados como se pode observar na fig. 2 .

Figura 2 - Objectivos Económicos

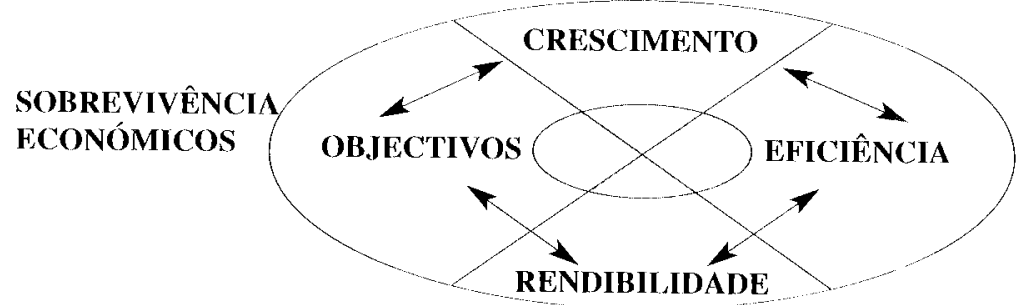

Fonte: Adaptado de E. Bueno Camposs

O objectivo de crescimento empresarial, é encarado numa perspectiva de longo prazo, porque em muitas ocasiões e situações críticas é difícil perceber as tendências dos acontecimentos futuros. Por isso é necessário planear objectivos a longo prazo, formular estratégias que

\footnotetext{
${ }^{3}$ Associação Espanhola de Contabilidade e Administração de Empresas.
} 
facilitem a rentabilidade a longo prazo, tendo que desenvolver novos produtos e serviços, para fazer frente a essas necessidades e ao mesmo tempo proporcionar aos clientes mais valor do que o oferecido pela concorrência.

\section{2 - Estratégias de crescimento sistemático}

Na realidade quase todas as empresas procuram crescer. Isto é especialmente verdadeiro para as empresas novas, que estão ainda numa fase inicial de seu desenvolvimento empresarial. Porém, para muitas empresas o crescimento é a parte de uma progressão caótica, que as incomoda ou mesmo as dirige para fora do negócio. Para se poderem identificar as necessidades e soluções de financiamento, a empresa deve consequentemente planear o processo de crescimento estratégico muito antes do seu início.

"Um bom plano de crescimento capta a visão de expansão da empresa. 1)irige-se ao produto e às combinações de mercado das intençōes que a empresa persegue, o tamanho que espera conseguir num determinado período de tempo, e, ainda mais importante, o know-how e as estruturas organizacionais que suportarão a expansão ou a diver'sificação", Krogh /Cusumano (2001).

Este plano estratégico tem sido utilizado para derivar os objectivos financeiros e planear a estratégia de financiamento. De acordo com Krogh/Cusumano (2001), existem três estratégias de crescimento sistemático diferentes, que podem ser executadas (sobrepondo ligeiramente) sequencialmente sobre a vida de empresas com sucesso.

\subsection{1 - Crescimento por "Scaling"}

Scaling é a menos sofisticada das estratégias de crescimento. É executada expandindo as actividades das empresas em torno das tecnologias do negócio de base e das ofertas já existentes, linhas de produtos e reforço do esforço de marketing através de canais de distribuição existentes. Ao perseguir uma estratégia de scaling, as empresas devem investir agressivamente. Muitas vezes o payoff destes investimentos será muito retardado no tempo. 


\subsection{2 - Crescimento por "Duplication"}

A estratégia de duplicação é construída no específico objectivo da expansão geográfica. Quando se implanta uma estratégia de duplicação, existe uma troca (trade-off) entre a padronização (isto é a utilização de idênticos processos e produtos na posição nova como na origem) e a localização (isto é adoptando as necessidades locais dos consumidores). Em termos das necessidades de financiamento, a execução de uma estratégia de crescimento por duplicação significa uma descontinuidade no objectivo da função financeira da empresa. Consequentemente o financiamento deve ser especificamente projectado para lidar com o momento de se mover de uma posição para outras posições. Para além da necessidade substancial de fïnanciamento do crescimento, são necessários os instrumentos financeiros de gestão do risco operacional e cambial.

\subsection{3 - Crescimento por "Granulation"}

A estratégia de crescimento por granulação é apresentada aqui apenas por uma questão de complementaridade. Devido às suas exigências de recursos encontra-se na maior parte em empresas mais velhas, grandes e apresenta-se certamente inútil para as start-up e para fïrmas no seu primeiro estágio de expansão. O "granulation” é uma aproximação tranquila de trabalho ainda quando as estratégias de Scaling e duplicating não são nunca mais praticáveis. Este poderia ser o caso quando existam demasiadas entradas de preços baixos no mereado (competição imitadora), a tecnologia do produto esteja já envelhecida, ou todas as posições possíveis tenham sido já integradas numa estratégia de duplicação.

Quando se implanta uma estratégia de granulação, as unidades de negócio independentes, as subsidiárias ou de spin-offs ${ }^{4}$ estão utilizando

Entendido como novas actividades económicas criadas no seio de empresas ou universidades e que acabam por adquirir independência e viabilidade próprias em termos jurídicos, técnicos e comerciais. Spin-off Industrial, estratégia industrial con o objectivo de favorecer a criação de empresas inovadoras, geradoras de valor acrescentado e riqueza no meio industrial em que se inserem e com elevado potencial de crescimento. Spin-off Académico, estratégia com o objectivo de promover o desenvolvimento da inovação e da tecnologia, pela criação de empresas e promoção do próprio emprego, bem como a diversilicação, de empresas já existentes pela relação biunívoca universidade empresa. 
os recursos da empresa (especialmente os sistemas de gestão do conhecimento) explorando novas áreas de actividades de negócio. As células de actividade não estão necessariamente relacionadas com o negócio de base da empresa. Para controlar o crescimento e assegurar o risco envolvido com esta estratégia, um conjunto de novos instrumentos têm que ser introduzidos como seja a avaliação e monitorização, e um novo partilhar de ferramentas do conhecimento

\section{2 - A ESTRUTURA DO CICLO DE VIDA FINANCEIRO}

A usual teoria empresarial atribui fases orientadas a um modelo de crescimento, quando representamos o desenvolvimento de uma empresa. Esta vista teórica do processo de criação e crescimento de novos riscos é subdividido em quatro fases (o start-up ${ }^{5}$, o crescimento elevado, a maturidade a estabilidade). Em analogia a esta estrutura, foi desenvolvida na figura 3 o chamado " modelo do ciclo de vida financeiro".

A figura 3 ilustra as diferentes fontes de capital mais importantes em determinados estágios de desenvolvimento, J.A.Timmons (1994).

Figura 3 - O ciclo de vida financeiro

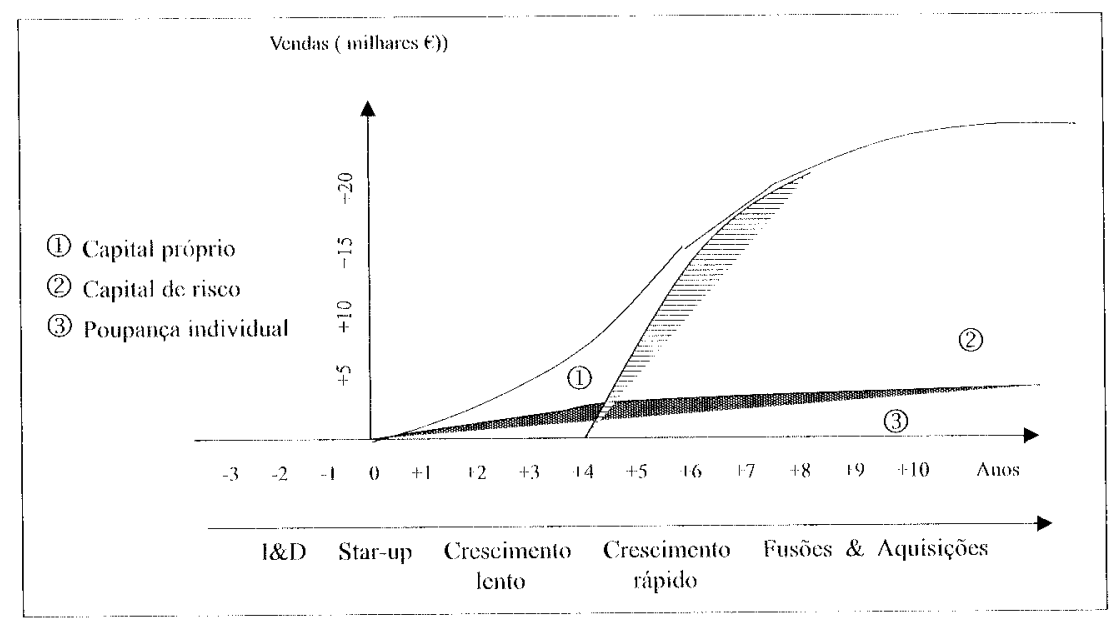

Fonte: Adaptado de J.A. Timmons.

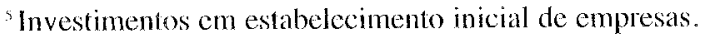




\section{1 - O Crescimento Sustentável}

No ponto anterior, foi indicado a importância de um plano estratégico de crescimento para determinar as exigências de recursos das empresas. Neste, iremos agora abordar com um olhar crítico, o relacionamento entre os objectivos do crescimento das empresas e as suas necessidades de financiamento.

\subsection{1 - A Taxa de Crescimento Sustentável}

De tempos a tempos, os negócios podem funcionar com problemas a não ser que se possa controlar o seu crescimento. O crescimento pode ser assim considerado metódico ou ser incontrolável. O crescimento incontrolável pode conduzir ao desempenho menos do que óptimo ou até mesmo a uma situação geradora de dificuldades fïnanceiras.

De facto, Adriano Freire (1995) refere-se ao crescimento a longo prazo das vendas, como um dos objectivos mais importantes das empresas, por reflectir não só o seu sucesso competitivo, mas também por servir os interesses dos seus constituintes e igualmente os interesses económicos ao possibilitar maiores economias de cscala e de experiência.

O crescimento sustentável, é visto como o crescimento real possível de modo a que a empresa possa alcançar e manter a funcionar a sua actividade sem qualquer tipo de problema ou dificuldade financeira.

Existem várias maneiras de se poder medir o crescimento sustentável, mas uma das medidas mais racionais é a do crescimento proporcional $^{6}$, que em primeiro lugar foi formulado por Hewlett - packard nos anos 50s.

João Carvalho das Neves (1992), apresenta para além deste modelo, o modelo aditivo e multiplicativo, cujas análises se mostram muito mais poderosas a nível da compreensão da origem da sustentação do crescimento ao longo dos anos em análise e transmite melhor uma ideia a nível dos riscos associados à respectiva taxa.

Stephen A. Ross (1996), definiu esta medida, através do preciso valor do crescimento sustentado, ou seja, da taxa máxima de cresci-

\footnotetext{
"Pressupõe uma relaçĩo constante entre o activo e as vendas.
} 
mento que uma empresa consegue manter sem aumentar o seu endividamento e utilizar apenas o seu capital próprio, calculado como:

$\mathrm{g}(\mathrm{s})^{7}=\mathrm{ROE}^{8} \mathbf{x}$ retenção de lucros

\subsection{2 - Crescimento real Vs Crescimento sustentável}

Se o crescimento sustentável for menor do que o crescimento real por um periodo prolongado, a empresa não pode sustentar a sua actividade sem "financiar" esse crescimento. De uma maneira ou de outra necessita de abrir caminho ao aumento dos lucros na empresa, quer incrementando a margem de lucro líquido ou aumentando o seu desempenho, ou pela "reserva" das fontes de risco, tais como o aumento do nível de endividamento, (TCS $<$ CR).

Quando o crescimento sustentável é maior do que o crescimento real, a empresa tem um potencial de engrenagem para cima. Se cair consistentemente abaixo do crescimento sustentável, estão está a passar por cima dos retornos para os accionistas, $(\mathrm{TCS}>\mathrm{CR})$.

\section{2 - O ciclo operacional de "Cash"}

É do domínio comum que para se iniciar uma actividade ou constituir uma empresa, é preciso "cash" e para fazer crescê-lo, exige-se ainda mais capital circulante", instalações, equipamentos e despesas operacionais. Mas, poucos compreendem que uma empresa rendível que tente crescer demasiado rapidamente, pode acabar por esgotar o cash, mesmo que os seus produtos gozem de grande sucesso no mercado. A pergunta-chave a esta questão é: Qual será a taxa de crescimento que uma empresa pode sustentar com o seu sistema operacional, e no caso, qual dos seus objectivos de crescimento estratégico estão mais ajustados à realidade, e/ou que fundos adicionais são necessários?

A taxa de crescimento sustentável (SFG) dá-nos exactamente esta informação. Ela é fundamentalmente influenciada por três elementos: $O$ ciclo operacional de cash da empresa (OCC), a quantidade de cash que

${ }^{7}$ Sustainable Grow Rate, taxa de crescimento sustentável.

${ }^{r}$ Return on Equity, taxal de rentabilidade dos Capitais Próprios.

"Compreende as rubricas de existências, realizável e disponível. 
é necessário para financiar cada ciclo e a quantidade de cash gerado por unidade vendida no ciclo. Na fig. 5, representamos os respectivos componentes do ciclo operacional de cash, cujos três factores no seu conjunto, determinam a taxa de crescimento sustentável de uma empresa.

Figura 4 - Componentes de un ciclo operacional de Cash

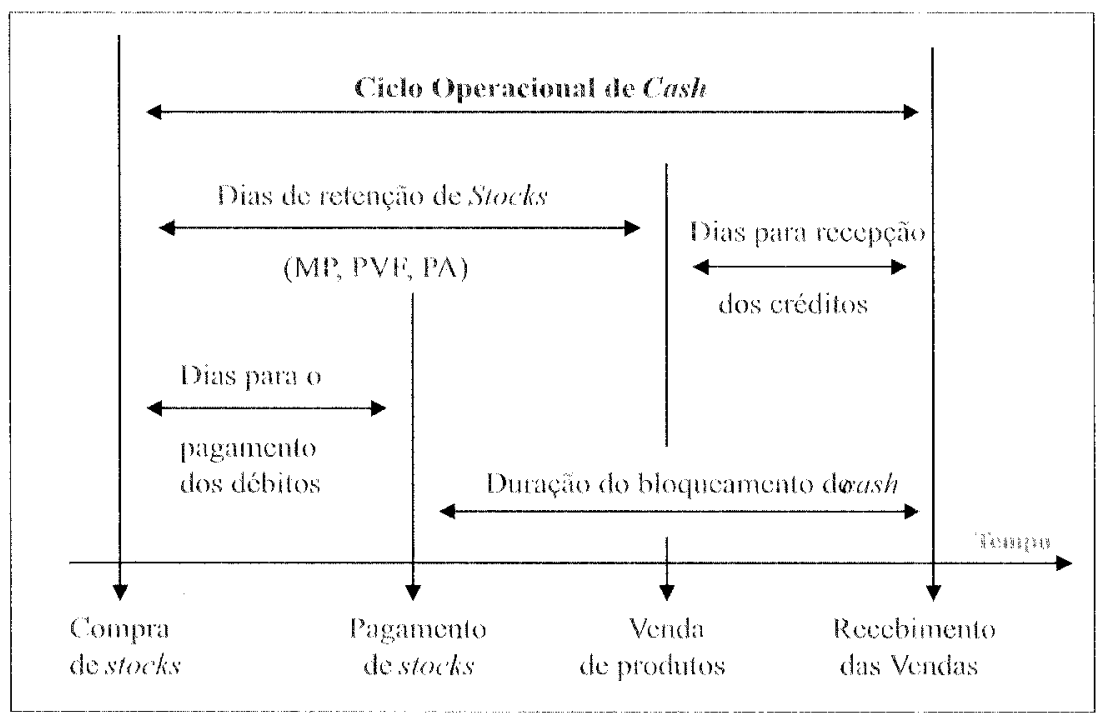

O ciclo operacional de cash da empresa consiste pois, no tempo durante o qual o dinheiro da empresa está bloqueado em stock e outros activos circulantes, antes que seja paga pelos produtos e serviços que produz.

Depois de determinar o OCC, temos que calcular a quantidade de dinheiro que realmente está bloqueado em cada ciclo de cash. O conponente aqui utilizado é o custo das existências vendidas e das matérias consumidas, considerado o mais pesado pelo seu bloqueamento no período.

O último elemento da SFG é a quantidade de cash que entra por cada ciclo em termos de cash gerado por cada unidade monetária vendida.

Neil C.Curchill e John W. Mullins (2001) determinam a taxa de crescimento sustentável, para a qual a empresa consegue sustentar o seu crescimento através das receitas que gera, sem ter de recorrer a financiamentos externos, ou seja equilibrar o consumo de cash com a própria 
facilidade em gerar cash e, mostram cono os três factores podem funcionar como alavancas manipuláveis para aumentar a capacidade de crescimento (acelerar o cash flow; reduzir os custos; elevar os preços e Utilizar em simultâneo os instrumentos de crescimento) e como instrumento de controlo de uma empresa, á nível das preocupações de crescimento dos gestores.

\section{3. - O Modelo financeiro de Donaldson}

Segundo Ansoff (1977), a empresa possui objectivos " económicos e sociais voltados para a maximização da eficiência do seu processo global de transformação dos recursos e, que se traduzem na interacção e na satisfação dos seus stakeholders.

De facto para a maioria das empresas, esses objectivos económicos exercem uma influência sobre o seu comportamento e constituem as principais metas explícitas usadas pela gestão no controlo e na orientação da sua actividade empresarial.

Ainda de acordo com Robert Schultz, (1972), o aumento dos resultados, a redução do risco e o aumento da competitividade constituem o meio para se alcançar os objectivos económicos através das estratégias de crescimento.

Na sequência, Donaldson publica a sua obra de fundo em 1984 , reflexo de una pesquisa aprofundada, demonstrando magistralmente, de que forma é que as empresas podem verificar a compatibilidade entre os seus objectivos financeiros e estratégicos com a realidade económica.

Para uma melhor compreensão da natureza e análise operacional do sistema de objectivos financeiros e das consequências estratégicas, apresentamos nos pontos seguintes a caracterização do modelo de Donaldson.

\subsection{1 - O modelo auto-sustentado}

Em conformidade, todos os objectivos financeiros que afectam o fluxo de fundos de uma empresa são o resultado de trade-offs. implícitos e explícitos entre os diversos interesses competitivos. Assim, qualquer empresa pode expressar esses objectivos de uma forma qualitativa.

"Entendido como regras de decisão que habilitam a gestão a medir e a orientar o desempenho da empresa no sentido da consecuçăo dos seus propósitos. 
Para encontrar o equilíbrio no sistema de objectivos financeiros, a oferta de fundos (capital) deve ser igual à procura de fundos. Assim, a afluência de fundos implícita nos objectivos das taxas de rendibilidade das empresas devem ser iguais à saída de fundos implícita nos objectivos das taxas de crescimento das vendas.

Este conceito pode ser expresso por uma equação matemática, conhecida por equação do crescimento auto sustentada, como condição de equilíbrio do sistema de objectivos financeiros. Assim esta equação, embora limitando o sistema de objectivos financeiros de gestão essencial a este conjunto de objectivos de uma empresa típica a quatro variáveis, pode ser representada do seguinte modo:

$$
g(S)=r\{\text { RONA + d (RONA - i })\}
$$

Composta pelas seguintes variáveis:

- taxa de crescimento das vendas, ou $g(S)$;

- ROI (return on investiment), utilizando o (return on net assets), ou RONA;

- rácio de lucros retidos (o complemento do objectivo de pagamento de dividendos), ou $r$;

- rácio de endividamento, ou $d$ (Passivo total / Capitais próprios);

- taxa de juro depois de impostos, $i$.

A equação inclui todos os elementos principais do sistema de objectivos financeiros para um determinado mercado de produtos, reflectindo a tensão contínua existente entre os objectivos de crescimento no lado esquerdo da equação e os objectivos de rentabilidade do investimento do lado direito.

\subsection{2 - O Ciclo estratégico}

Para caracterizar estas prioridades básicas da empresa, apresentamos na figura 7 , o ciclo de vida das prioridades fïnanceiras.

O ciclo estratégico está associado ao ciclo de vida dos produtos ${ }^{1 "}$, que caracteriza o ciclo de vida típico das mudanças nas prioridades empresariais.

\footnotetext{
"Que estabelece a relação entre a taxa de crescimento e os respectivos cash flows.
} 
Expresso nos termos da figura 7,0 ciclo estratégico pode ser dividido em 5 fases. Durante a primeira ou fase de entrada, as taxas de crescimento e do RONA são mais baixas do que o desejado, e a última pode até ser negativa durante um certo período de tempo.

Figura 5 - Ciclo de vida das prioridades financeiras da empresa

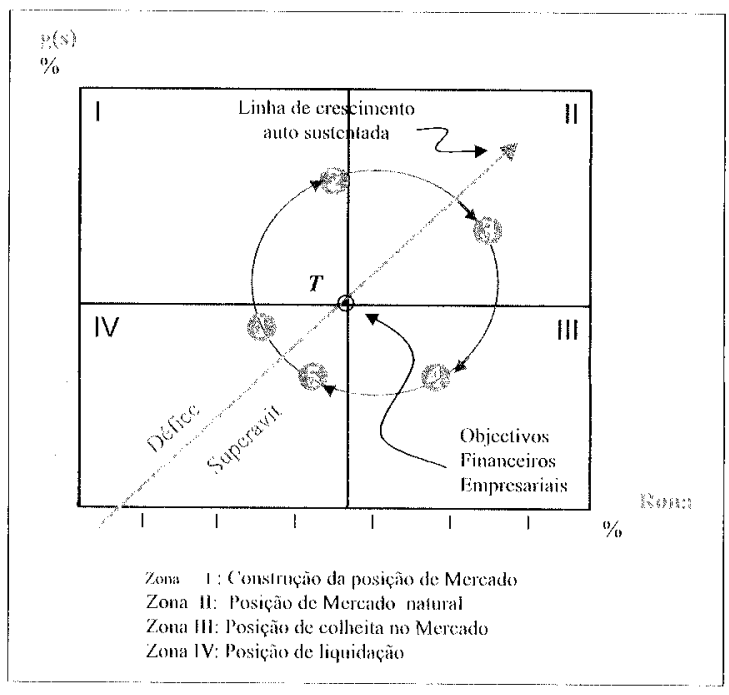

Fonte : Gordon Donaldson

$\mathrm{Na}$ estrutura de crescimento do mercado, com o aperfeiçoamento das vendas, a unidade estratégica de negócio move-se para cima e para a direita ao longo do l quadrante, embora o crescimento seja elevado e o RONA abaixo do objectivo estipulado.

Se os produtos forem bem sucedidos no mercado, a unidade estratégica de negócio continua o seu ciclo dentro do II quadrante, onde todos os objectivos são mais do que satisfeitos.

As empresas movem-se de uma zona para outra, procurando um elevado crescimento e um elevado RONA. Ambos os objectivos podem ser melhorados, deslocando o desempenho ao longo da diagonal. Contudo, muitas vezes o crescimento e o investimento precedem o RONA e podem até mesmo requerer sacrifícios a curto prazo.

Ainda que o crescimento decline, como acontece na fase 4, RONAs superiores são obtidos através dos mercados de títulos, até que a unidade estratégica de negócio entre no último estágio. Aqui, a empresa deve 
penetrar em novos e desconhecidos mercados de produtos para estabelecer uma lucrativa e estável quota de mercado.

Respondendo às forças iniciais e às prioridades do crescimento e diversificação do mercado de produtos, as empresas tornam-se mais dependentes do mercado de capilal externo e devem dar ênfase ao RONA e ao lucro dos accionistas como paga dessa dependência.

Depois de recuperada a sua auto-suficiência, a empresa pode movimentar-se de novo para uma política de dívida conservadora e incrementar o pagamento de dividendos. Tornar-se-á então menos dependente no mercado externo e da prioridade dos seus objectivos.

\section{3 - METODOLOGIA E INSTRUMENTOS DE MUDANÇA}

\section{1 - As variáveis}

O objectivo primário deste trabalho consiste pois em:

"Equacionar as variáveis determinantes do sistema de objectivos financeiros a nível do planeamento financeiro das PME's, procurando averiguar se os resultados obtidos se enquadram ou não nas sugestões desenvolvidas e teorizadas através da diversa literatura especializada e da moderna Teoria Financeira".

Assim, optamos por utilizar as seguintes variáveis cono determinantes do sistema de objectivos financeiros $(S O F)$ : o crescimento sustentável; a rentabilidade; a tesouraria e o índice $Z$.

\subsection{1 - O Crescimento sustentável}

Considerando que as empresas frequentemente fazen previsões explícitas de crescimento no seu planeamento financeiro, Donaldson (1984), apresentou o seu modelo para ilustrar as ligações entre a capacidade de crescimento de uma empresa e a sua política financeira, e cuja caracterização e compreensão da natureza e análise operacional do sistema de objectivos financeiros e das suas consequências estratégicas, foi apresentado no ponto 2.3 .

\footnotetext{
"A laxa de crescimento sustentável de uma empresa depende do seu nível de rentabilidade e da sua política de financiamento.
} 
Assim, considerada como variável dependente ${ }^{12}$ o crescimento sustentável, é entendido como o crescimento real das vendas que é possível obter de modo a que uma empresa possa alcançar e manter a funcionar a sua actividade sem qualquer tipo de problema ou dificuldade financeira, e que visa satisfazer os interesses dos seus stakeholders e reforçar a sua competitividade. Interiorizado o objectivo de crescimento operacional a longo prazo, torna-se difícil retroceder nesta lógica de expansão empresarial, na medida em que a estagnação ou queda das receitas de venda, conduzem de imediato à deterioração dos resultados o que poderá até dar origem à própria cessação da actividade.

Através da variação do volume de negócios, ć possível analisar e quantificar o crescimento sustentável. Dados, a margem de lucro (p), o índice de distribuição do lucro (d), a relação entre o capital alheio e o capital próprio (L), e o índice de necessidade de activos (T), será possível determinar a taxa de crescimento sustentável que é compatível com os valores pré determinados destas quatro variáveis, através da seguinte formulação, apresentada por Stephen A. Ross et. al.(1996):

$$
\begin{aligned}
& \Delta S=\text { p. }(1-d) \cdot(1+L)^{\prime 3} \\
& S_{0} \cdot T-p \cdot(1-d) \cdot(1+L)
\end{aligned}
$$

Segundo esta formula, a laxa de crescimento de uma empresa depende dos resultados retidos e da estrutura de financiamento, mas a rendibilidade é aqui computada em função das vendas e não do activo, como foi definida no ponto 3.5.1. (o modelo auto-sustentado de Donaldson), através da variação dos activos.

Tendo subjacente a evolução da empresa, que tcrá como tendência natural o crescimento e procurando obter uma resposta à questão formulada no capítulo anterior, "Qual será a taxa de crescimento que una empresa pode sustentar com o seu sistema operacional, e no caso, qual dos seus objectivos de crescimento estratégico estão mais ajustados à rea-

${ }^{13} \mathrm{~T}=$ Rácio do Activo total / Vendas; $\mathrm{p}=$ Margem de lucro líquido sobre as vendas (rentabilidade das vendas); $\mathrm{d}=$ - Rácio de retenção de hucros ( 1 - rácio de dividendos (dividendos / res. lía.)); $L=$ Rácio de endividamento (Passivo / Capital próprio); $S_{0}=$ Vendas do próprio ano; $S_{1}=$ Vendas do ano anterior; $\mathrm{S}=$ Acréscimo de vendas $\left(\mathrm{S}_{1}-\mathrm{S}_{0}=\right.$ $\triangle S) ; L r=L$ ucros retidos $=$ Lucro líquido. rácio de retençăo de lucros $=S_{1} \cdot p \cdot(1 \cdots \mathrm{d})$; $L L=$ Lucro lícpuido $=S_{1} \cdot p$. 
lidade, e/ou que fundos adicionais são necessários?", consideramos que do ponto de vista dinâmico o modelo de Churchill \& Mullins nos transmite melhor esta informação sobre a realidade financeira das empresas.

No entanto, e tendo como princípio a prudência, devemos confrontar os resultados obtidos com aqueles que poderemos obter através da equação definida pelo Modelo de Donaldson (variação do volume de vendas). Assim, obtido o valor relativo da taxa de crescimento sustentável, procuramos determinar o crescimento real das vendas (diferença entre as vendas do exercício do ano $\mathrm{N}$ e as vendas do exercício do ano $\mathrm{N}-1$ ), por forma a podermos tecer considerações sobre a sua evolução e poder representá-las graficamente.

\subsection{2 - A Rendibilidade}

Seja qual for o indicador utilizado para o conceito, tal como refere Caldeira Menezes (1993), "é predominantemente relativo no sentido em que se relaciona os resultados obtidos com os meios utilizados para a sua consecução".

E ainda tal como indica João Carvalho das Neves (1992), "a rendibilidade do investimento é um indicador do desempenho dos capitais totais investidos na empresa, (...) que determina a sobrevivência financeira da empresa a longo prazo e a atracção de capitais, quer alheios quer próprios."

A rendibilidade líquida dos activos (RONA), é a variável independente com mais impacto na determinação da taxa de crescimento sustentável, sendo utilizado como indicador o quociente entre os resultados líquidos e o total do activo líquido.

Procurando encontrar o equilíbrio do sistema de objectivos financeiros, a oferta de fundos deve ser igual à procura de fundos, ou seja, a afluência de fundos implícita nos objectivos de rentabilidade das empresas deve ser igual à saída de fundos implícita nos objectivos das taxas de crescimento das vendas.

Este equilíbrio reflecte pois a tensão contínua existente entre os objectivos de crescimento do lado esquerdo da equação e os objectivos de rendibilidade do investimento do lado direito.

Procurando perceber as implicações estratégicas de níveis crescentes de rendibilidade, ou seja, a relação entre os resultados operacionais retidos na empresa e a competitividade (capacidade de superar a con- 
corrência no mercado), através de um elevado crescimento sustentado, representamos graficamente estas duas varáveis.

Nesta linha de pensamento, procuramos identificar e caracterizar o ciclo de vida das prioridades financeiras das empresas através do ciclo estratégico de Donaldson, apresentado no ponto 2.3.2.

\subsection{3 - A Tesouraria}

A escolha deste indicador como instrumento de análise porque, expressa o sentido dinâmico da vida da empresa que em cada momento regista um valor resultante dos fluxos financeiros decorrentes da actividade e das operações financeiras e que se espelham nas disponibilidades da empresa.

Por um lado, a tesouraria vista na perspectiva dos grandes agregados que conferem estabilidade ou equilíbrio estrutural, ligadas às políticas da empresa no que respeita aos investimentos e às condições de gestão da exploração e que explica o recurso à equação fundamental da tesouraria, $T=F M-N F M$.

Por outro lado, o aspecto dos efeitos e consequências dos fluxos financeiros, que se reflectem na situação da tesouraria ao nível de saber qual o volume adequado ao normal e eficaz funcionamento da empresa, e que se traduz na abordagem expressa da igualdade, $\mathrm{T}=\mathrm{AT}-\mathrm{PT}^{14}$.

\subsection{4 - O Índice Z}

Aplicando a análise discriminante, Altman (1983) construiu uma função discriminante largamente aplicada na prática e que se popularizou como o $Z$ - Score Model. Esta função é uma combinação linear de vários rácios, e que permitem o cálculo de um score para cada empresa e/ou período de análise, donde resulta uma avaliação sobre a sua possibilidade de rotura financeira:

$$
\mathrm{Zi}=1.2 \mathrm{X}_{1 \mathrm{i}}+1.4 \mathrm{X}_{2 \mathrm{i}}+3.3 \mathrm{X}_{3 \mathrm{i}}+0.6 \mathrm{X}_{4 \mathrm{i}}+1.0 \mathrm{X}_{5 \mathrm{i}}{ }^{1.5}
$$

\footnotetext{
${ }^{14}$ A Tesouraria Líquida é igual à diferença entre o Activo de Tesouraria e o Passivo de Tesouraria.

${ }^{15}$ Os rácios considerados relevantes no modelo, são os seguintes: $X_{1 i}$, Fundo de maneio $\div$ Activo total; $X_{2 i}$, Resultados Retidos $\div$ Activo total; $X_{3 i}$, Resultados operacionais $\div$
} 
Quando o crescimento da empresa for excessivo, convém analisar o risco de rotura financeira e que se traduz numa série de indicadores de gestão com ponderações predeterminadas para dar origem a um indicador composto da capacidade económica e financeira da empresa. Em função do valor apurado, Altman apresentou uma tabela para a qual estabeleceu classes de intervalos de $Z_{\mathrm{i}}$, e para os quais teceu as seguintes conclusões:

- para $Z_{\mathrm{i}} \geq 3,0-$ A empresa está de boa saúde financeira e sem risco de rotura financeira;

- para $2,7 \leq Z_{i} \geq 3,0-A$ empresa sobrevive mas com algum risco de rotura financeira;

- para 1,8 $\leq Z_{i} \geq 2,7$ - A empresa apresenta elevado risco de rotura financeira num espaço curto de tempo e requer atenção especílïca;

- para $Z_{i} \leq 1,8-$ A empresa está tecnicamente em rotura financeira. No entanto, este indicador deve ser utilizado com cuidado, não só porque se trata de um rácio que por si só nada significa, servindo apenas para detectar anomalias, mas também porque não deve ser prescrita por indivíduos estranhos à empresa, mas sim definida pela gestão em função das suas especificidades, dos seus objectivos e com base na sua capacidade de gerar fluxos monetários.

\section{2 - OS RESULTADOS}

\subsection{1 - Considerações prévias}

Relativamente aos resultados obtidos, optamos por descrever apenas aquelas empresas cujos valores assumidos para as variáveis em estudo, indiciam capacidade de análise e reflexão adequadas aos objectivos enunciados e propostos.

Devemos referir que, embora pese no modelo de Churchill \& Mullins adoptado na determinação da TCS, um certo grau de sistematização em função dos dados apresentados, no que respeita à duração de bloqueamento de cash, relativamente às "despesas operacionais", optamos por um prazo médio comum de 45 dias, por considerarmos que as

Activo total $X_{4 i}$, Valor de mercado do Capital Próprio $\div$ Valor de mercado do Capital Alheio; $\mathrm{X}_{5 i}$, Vendas $\div$ Activo total. 
rubricas constituintes (encargos com salários, custos de Marketing, energia, combustíveis, transportes c outras), são pagas ao longo do ciclo operacional num prazo não superior a este.

\subsection{2 - Análise e reflexão do SOF / empresa}

\subsubsection{1 - Estrutura Financeira 100}

\begin{tabular}{|c|c|c|c|c|}
\hline & 1998 & 1999 & 2000 & 2001 \\
\hline RONA & 1,46 & 1,81 & 1,44 & 1,87 \\
\hline TCS & 4,18 & 6,86 & 6,98 & 8,33 \\
\hline CR & 67,17 & $-5,09$ & 16,44 & 3,27 \\
\hline
\end{tabular}

Relativamente aos valores apresentados no quadro resumo da estrutura financeira da empresa 100 , podemos verificar numa primeira análise, que é positiva e contínua a evolução da TCS ao longo do período em análise, o que denota um certo equilíbrio a nível do seu desempenho económico, apesar das oscilações bastante irregulares manifestadas pela evolução do seu CR, como se pode observar no seguinte gráfico:

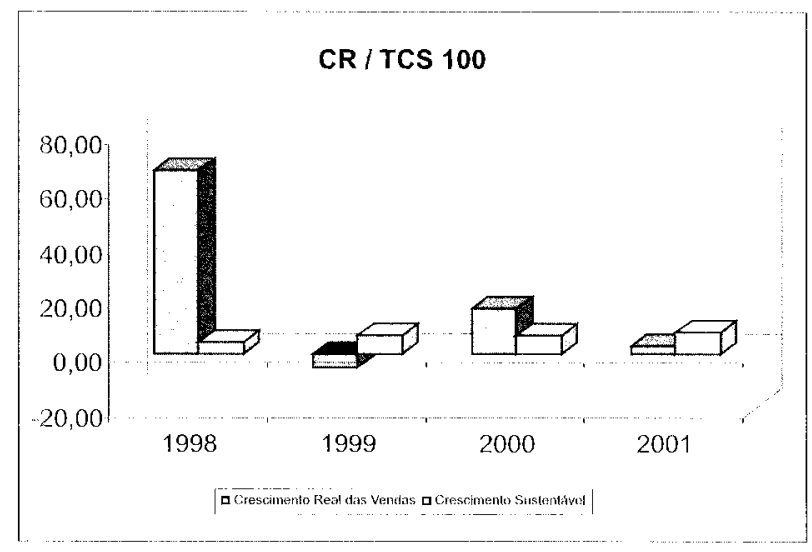

Podemos confirmar este equilíbrio sustentado ao verificarmos que apesar do ciclo operacional de cash (OCC) ser de 210 dias " (ver,

\footnotetext{
"Considerado muito longo, mas normal para o sector de actividade em que se encontra inserida, Curlumes.
} 
A: 100), o bloqueamento real de cash desta empresa é de apenas 59 dias (ver A: 100 ), para o ano de 2001 .

A rendibilidade líquida dos activos (RONA), reflecte também este equilíbrio da TCS, ao apresentar valores mais ou menos estáveis ao longo do período de análise.

Do ponto de vista do equilíbrio do Sistema de Objectivos Financeiros (SOF), ou seja, entre os objectivos de crescimento e os objectivos de rendibilidade do investimento total, verificamos que a empresa se posiciona no quadrante competitivo de mercado natural, com uma evolução muito positiva, mas afastando-se da posição de colheita de mercado $(1,46 ; 4,18)$, conforme se pode observar pelo seguinte gráfico:

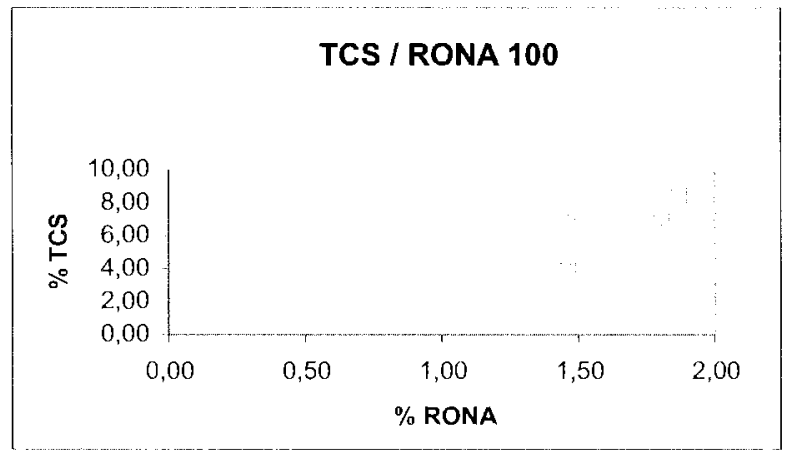

Relativamente à tesouraria, embora a empresa registe um valor negativo resultante dos fluxos financeiros decorrente da actividade e das operações financeiras de carácter intensivo, para todos os anos em análise, o que necessariamente pode não significar uma ruptura financeira, dependendo da velocidade dos fluxos financeiros e do montante e cadência de reembolso dos empréstimos e obtenção de outros em substituição e o que implica a gestão de um risco. É, neste sentido, cue $o$ valor apresentado para $\mathrm{o}$ índice $Z$, vem precisamente reforçar a ideia da assunção de riscos elevados o que passa pela gestão específica e cuidada.

\section{4 - CONCLUSÕES GERAIS E PERSPECTIVAS FUTURAS}

Através dos resultados obtidos, realçamos o enquadramento das sugestões desenvolvidas e teorizadas pela diversa literatura especializa- 
da e da moderna Teoria Financeira, nomeadamente no que se refere às perspectivas segundo:

- a dinâmica introduzida pelo modelo de Curchill e Mullins, que assume unła importância crucial a nível do objectivo operacional de crescimento e da realidade sobre a estrutura financeira das empresas e da sua evolução no mercado;

- a dinâmica introduzida pelo modelo de Donaldson, no que se refere à relação entre os resultados operacionais retidos e a competitividade, ou seja, as respectivas implicações estratégicas espelhadas na respectiva representação gráfica, para além do equilíbrio do sistema de objectivos financeiros estabelecido pelo RONA.

Perspectivas estas, consideradas essenciais para se poder construir novas vantagens competitivas e particularmente relevante em relação às PME's, e para as quais se colocam novos desafios e se geram novas oportunidades de mercado.

Com este estudo, para além da inventariação de alguns dos principais atributos sugeridos pelas diferentes teorias como potenciais determinantes do sistema de objectivos financeiros, obtivemos como resultado duas importantes contribuições:

- a primeira relativa à metodologia para a operacionalização empiricamente do sistema de objectivos financeiros e a respectiva validação para uma PME, constituindo o desenvolvimento adequado para futuras análises;

- a segunda contribuição é a própria identificação empírica das configurações que reflectem o sistema de objectivos financeiros das empresas industriais de curtumes e fornece um meio de comparação para o desenvolvimento para futuros estudos. 


\section{BIBLIOGRAFIA}

ALTMAN, E.I., R.G. Haldeman and P. Narayanan, (1977), Zeta Analysis : A new Model to Identify Bankruptcy Risk of Corporation, Journal of Banking and Finance, June 1977, pág. 29 a 54.

ANSOFF, H. Igor, (1977) Estratégia Empresarial, McGraw-Hill do Brasil.

AECA, (1996), Principios de Organizacion y Sistemas - Crescimento de la Empresa : Modalidades y Esratégias, Documento n. 6, 2." Edição, Madrid.

AECA, (1996), Principios de Organizacion y Sistemas - La Competitividad de la Empresa, Documento n.' 4, 3." Edição, Madrid.

BREALEY, Richard A. e Myers, Stewart C., (1992), Princípios de Finanças Empresariais, 3." Edição , Mc Graw-Hill de Portugal.

CAMPOS, E.Bueno, (1993) Curso Básico de Economia de la Empresa. Un enfoque de organización, Pirámide, Madrid.

CARDOSO, Luís, (1992), Gestão Estratégica das Organizações : Ao encontro do $3^{\circ}$ Milénio, 3." Edição, Verbo Editora, Lisboa.

CERVO, Armando Luís, Bervian Pedro Alcino, (1996) Metodologia Científica, 4." Edição, Makron Books, São Paulo.

CHURCHILL, Neil C. e Lewis, Verginia L., (1983), The Five Stages of Small Business Growth, Havard Business Review, May / June, pág. 30 a 50 .

CHURCHILL, Neil C. e Mullins, John W., (2001) How fast can your company afford to grow, Havard Business Review, Volume 79, n.' 5, Maio 2001, págs. 135-143, Boston.

CUSUMANO, Michael A.,Georg Von Krogh, Managing fast growth, Mit Sloan Management Review, Winter 2001, págs. 53 a 61 , Cambridge.

DONALDSON, Gordon, (1978), New frame work for corporate debt policy, Havard Business Review, Set-Out 1978.

DONALDSON, Gordon, (1984) Managing Corporate Wealth : The Operation of a Comprehensive Financial Goals System, Plaeger Publishers, New York.

FOSTER, George (1986), Financial Statement Analysis, 2." Edição, Prentice Hall Internacional Editions, London. 
FREIRE, Adriano, (1995) Estratégia: Sucesso em Portugal, Editorial Verbo, Lisboa.

GITMAN, Lawrence J., (1978), Principles of Managerial Finance, Harper \& Row Publishers Inc., Nova Iorque.

MENEZES, H. Caldeira, (1993), Princípios de Gestão Financeira, 4." Edição, Editorial Presença, Lisboa.

MEYER, Henry, (1977) Corporate Financial Planning Models, John Wiley \& Sons, New York.

NEVESS, João Carvalho, (1992) Análise Financeira - Métodos $e$ Técnicas, 6." Edição, Texto Editora, Lisboa

PENROSE, Edith, (1995) The Theory of the Growth of the Firm, 3. Edição, Oxford University Press, Oxford.

ROSS A.Stephen, Westerfield, Randolph W. e Jaffe, Jeffrey, (1996) Corporate Finance, 4. 'Edição, Irwin, London.

SANTOS, Arlindo F., (1981), Análise Financeira : Conceitos, técnicas e aplicações, INIEF, Lisboa

SCHULTZ, Robert, (1972), Basic Financial Management, 2. Edição, Intertext Educational Publixhers, Seraton.

TIMMONS, J.A.(1994), New venture creation entrepreneurship for the $2 I^{\text {st }}$ century, 4 . Edição, Burr Ridge, Ill. Et al. : Irwin. 


\section{ANEXO}

ESTRUTURA FINANCEIRA DA EMPRESA 100

\begin{tabular}{|c|c|c|c|c|c|c|c|c|c|c|}
\hline & & & & & & & \multicolumn{4}{|c|}{$10^{\text {"Tnomlos }}$} \\
\hline Rúbricas & 2001 & $\%$ & 2000 & $\%$ & 1999 & $\%$ & 1998 & $\%$ & 19997 & $\%$ \\
\hline Demonstração de Resul & & & & & & & & & & \\
\hline Vendas & 335.944 & 97,3 & 2.261 .988 & 96,3 & 1.942 .702 & 96,3 & 2.046 .9319 & 95,2 & 1.224 .474 & 87.4 \\
\hline Outros provetios & 65.780 & 2.7 & 86.509 & 3,7 & 74.760 & 3.7 & 102.953 & 4,8 & 176.623 & 12,6 \\
\hline rotal dos proveitos & 2.401 .724 & & 2.348 .497 & & 2.017 .463 & & 2.149 .884 & & 1.401 .097 & \\
\hline Custo das Vendas & 1.526 .703 & 63,6 & 1.553 .957 & 66,2 & $\$ .309 .310$ & 64.9 & 1.466 .984 & 68,2 & 857.410 & 61,2 \\
\hline Rest & 875.021 & 36.4 & 794.541 & 33,8 & 708.152 & 35,1 & 682.900 & 31,8 & 543 & 38,8 \\
\hline cionais & 745 & 35,2 & 770.360 & 32,8 & 684.696 & 33.9 & 662.390 & 30.8 & 534.836 & 38.2 \\
\hline Resultados liquidos & 29.276 & 1.2 & 24.180 & 1,0 & 23.456 & 1,2 & 20.509 & 1,0 & 8.851 & 0,6 \\
\hline Bal & & dias & & dias & & dias & & dias & & dias \\
\hline Disp & 03 & & 2.691 & & 4.807 & & 4.350 & & 15.129 & \\
\hline Crè & 6 & 32 & 7 & 64 & 178.377 & 34 & & 55 & 98.863 & 29 \\
\hline Existências (2) & 745.792 & 178 & 43 & 180 & 643.728 & 179 & 377 & 174 & 526.715 & 224 \\
\hline $\begin{array}{l}\text { Amobitizado } \\
\text { Activo Total }\end{array}$ & $\begin{array}{r}966.811 \\
596.472 \\
1.563 .284 \\
\end{array}$ & 210 & $\begin{array}{r}1.106 .681 \\
573.116 \\
1.679 .796 \\
\end{array}$ & 234 & $\begin{array}{r}826.91 \% \\
471.822 \\
1.298 .734 \\
\end{array}$ & 2.13 & $\begin{array}{r}1.010 .366 \\
391.956 \\
1.402 .322 \\
\end{array}$ & 229 & $\begin{array}{r}640.707 \\
390.912 \\
1.031 .619 \\
\end{array}$ & 254 \\
\hline Capital & & & $\overline{00}$ & & 400.000 & & 00 & & 00 & \\
\hline Lueros retidos & 188.605 & & 156.888 & & 133.4 & & 22 & & 104.071 & \\
\hline Resultado líquido & 29.276 & & 24.180 & & 23.456 & & 20.509 & & 8.851 & \\
\hline Capital Proprio & 618.845 & & 68 & & 556.888 & & 533.431 & & 612.922 & \\
\hline Débitos (3) & 633.235 & 151 & 747.112 & 175 & 506.219 & 141 & 510.364 & 127 & 303.746 & 129 \\
\hline Eimpréstimo $\mathrm{c} / \mathrm{p}$ & 172.298 & & 204.210 & & 177.221 & & 2.17 .226 & & 153.650 & \\
\hline Passivo comonte & 805.533 & & $951.32 ?$ & & 683.440 & & 727.590 & & 457396 & \\
\hline D'ividas $m / l / p$ & 138.905 & & 147.406 & & 58.406 & & 141.301 & & 01 & \\
\hline C.Próprio + Passivo & 1.563 .284 & & 1.679 .796 & & 1.298 .734 & & 1.402 .322 & & .031 .619 & \\
\hline
\end{tabular}

(1) $206.010 / 2.335 .944 \times 365$ dias

(2) $-745.792 / 1.526 .703 \times 365$ das

(3) $-633.235 / 9.520 .703 \times 365$ dias

\section{Tesouraria \\ FM (C.Permani. Imobilizado liq.) \\ NFM (Capital Cire. - Psssivo Cirs) \\ TL (FM - NFM)

\begin{tabular}{rr}
161.278 & 155.359 \\
318.572 & 356.878 \\
\hline-157.295 & -201.519 \\
\hline \hline
\end{tabular}

$\begin{array}{r}143.472 \\ 315.886 \\ \hline-172.414 \\ \hline\end{array}$ \\ 282.776 \\ 183.311 \\ 495.653 \\ 321.832
$-\frac{138.521}{4}$
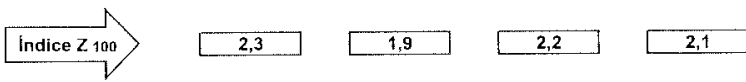

CR / TCS 100

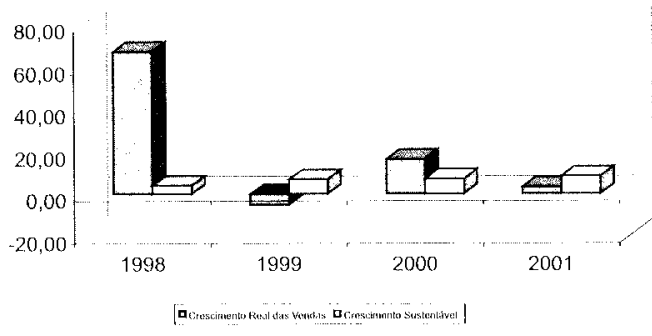


Cálculo da Taxa de Crescimento Sustentável

\begin{tabular}{|c|c|c|c|c|}
\hline Rúbricas & 2001 & 2000 & 1999 & 1998 \\
\hline Duração do bloqueamento do cash & dias & dias & dias & dias \\
\hline Créditos & 32 & 54 & 34 & 55 \\
\hline Existências & 178 & 180 & 179 & 174 \\
\hline OCC & 210 & 234 & 213 & 229 \\
\hline Débitos & 151 & 175 & 141 & 127 \\
\hline Custo das vendas & 59 & 59 & 72 & 102 \\
\hline Despesas operacionais & 45 & 45 & 45 & 45 \\
\hline Estrutura de Exploração (DR) & $\%$ & $\%$ & $\%$ & $\%$ \\
\hline Vendas & 100,0 & 100,0 & 100,0 & 100,0 \\
\hline Custo das vendas & 63,6 & 66,2 & 64.9 & 68,2 \\
\hline Despesas operacionais & 35,2 & 32,8 & 33,9 & 30,8 \\
\hline Custos totais & 98,8 & 99,0 & 98,8 & 99.0 \\
\hline Resultados (cash) & 1.2 & 1,0 & 1,2 & 1,0 \\
\hline \multicolumn{5}{|l|}{ Cash bloqueado $p$ / unid. m. vendida } \\
\hline Custo das Vendas (4) & 0,178 & 0,167 & 0,219 & 0,303 \\
\hline Custos de Exploração (5) & 0,075 & 0,063 & 0,072 & 0,061 \\
\hline Cash necessário para cada $\mathbf{O C C}$ & 0,254 & 0,229 & 0,291 & 0,364 \\
\hline Cash gerado $p /$ unid. m. vendida & 0,012 & 0,010 & 0,012 & 0,010 \\
\hline \multicolumn{5}{|l|}{ Cálculo da taxa de TCS } \\
\hline Taxa de SFG no OCC (6) & 4,80 & 4.49 & 4,00 & 2,62 \\
\hline OCC por ano (7) & 1,73 & 1.56 & 1,71 & 1,60 \\
\hline Taxa de SFG anual (8) & 8,33 & 6,98 & 6,86 & 4,18 \\
\hline
\end{tabular}

(4) $0,636 \times(59: 210) ;(5) 0,352 \times(45: 210)$

(6) $0,012: 0,254 \times 100:(7) 365: 210$

(8) $4,80 \times 1,73$

\section{Sumula da TCS da 100}

CR 100 - Crescimento real das vendas

TCS 100 - Tx.Cres.Sust.(Neil Churchill)

RONA (RL / Activo)

$p=$ Rentab.das vendas ( RL / Vendas)

$L=$ Rácio de endividamento (Pas/Cp)

$T$ = Rácio do activo / vendas

$\triangle \mathrm{S} / \mathrm{S} \mathrm{O}$

$\begin{array}{cccc}\mathbf{3 , 2 7} & \mathbf{1 6 , 4 4} & \mathbf{- 5 , 0 9} & \mathbf{6 7 , 1 7} \\ \mathbf{8 , 3 3} & \mathbf{6 , 9 8} & \mathbf{6 , 8 6} & \mathbf{4 , 1 8} \\ & & & \\ \mathbf{1 , 8 7} & \mathbf{1 , 4 4} & \mathbf{1 , 8 1} & \mathbf{1 , 4 6} \\ & & & \\ & & & \\ 0,013 & 0,011 & 0,012 & 0,010 \\ 1,526 & 1,891 & \mathbf{1 , 3 3 2} & 1,629 \\ 0,669 & 0,743 & 0,669 & 0,685 \\ \mathbf{4 , 9 7} & \mathbf{4 , 3 4} & \mathbf{4 , 4 0} & \mathbf{4 , 0 0}\end{array}$

TCS / RONA 100

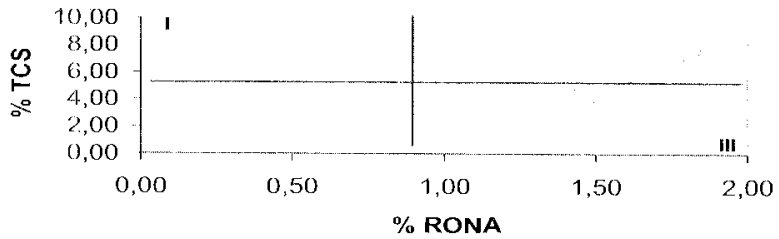

